\title{
Empirical Analysis of "Volatility Surprise" between Dollar Exchange Rate and CRB Commodity Future Markets
}

\author{
Ching-Chun Wei ${ }^{1}$ \\ ${ }^{1}$ Department of Finance, School of Management, Providence University, Taichung City, Taiwan \\ Correspondence: Ching-Chun Wei, Department of Finance, School of Management, Providence University, \\ Taichung City, Taiwan. Tel: 886-4-2632-8001. E-mail: ccw@pu.edu.tw
}

Received: July 9, 2016

Accepted: July 29, 2016

Online Published: August 25, 2016

doi:10.5539/ijef.v8n9p117

URL: http://dx.doi.org/10.5539/ijef.v8n9p117

\begin{abstract}
This paper used the five multivariate GARCH models (including BEKK, CCC, DCC, VARMA-CCC and VARMA-DCC) to analyze the mean and volatility interaction of volatility surprise between US dollar exchange and CRB future index (including agricultural, energy, commodity and precious metal equity index). The empirical findings exhibit that significant own short and long-term persistence effects and the cross-markets volatility surprise spillover short and long-term persistence effects between dollar exchange rate and CRB commodity future equity index markets in five multivariate GARCH models. Besides that, the residual diagnostic test indicated that VARMA-DCC models is the best suitable model to modeling the dollar exchange rate with CRB commodity equity index.
\end{abstract}

Keywords: MGARCH,volatility surprise, dollar exchange rate, CRB commodity future market

\section{Introduction}

Previous research of the volatility has long been a topic of interest to both policy makers and practitioners. The changes of variance (volatility) reflect the arrival of new information and the extent to which the market evaluates and assimilates new information. Turning to the volatility transmission, the transmission pattern in variance provides an insight concerning the characteristics and dynamics of economic and financial prices, and such information can be construct better econometric models describing the temporal dynamics of the time series.

To be a policy makers who are concerned in the determinants of volatility and in its spillover effects on real activity. However, a market practitioners are interesting in the direct effects of time varying volatility exerts on the pricing and hedging of financial derivatives (Aboura \& Chevallier, 2015).

Ross (1989) show that volatility transmission that it is the volatility of an asset price, not the asset's price change, that is related to the rate of information flow to the market. In finance, the concept of "volatility surprise" is usually emphasized on the predictable variance, for example, the conditional variance or the implied variance. Engle (1993) stated that because of the difference that cannot be forecast between the squared residuals and conditional variance therefore it is worthy of analysis. Such a quantity has been called a "volatility surprise". This concept was first to interpret this quantity as a volatility surprise because it lags behind the conditional variance by Hamao, Masulis, and Ng (1990). Aboura and Chevallier (2014) used the asymmetric DCC with exogenous variable(ADCCX) model by updating the concept of volatility surprise to capture cross-market relationships. The results provide strong evidence of spillover effects coming from the "volatility surprise" component across equities, bonds, foreign exchange rates and commodity markets from 1983 to 2013.

The sharp increase in agricultural commodity prices in the recent year has received attention interest to both academic and practioners. There are two factors to explain the increasing of agricultural commodity prices. One is the demand-side factors and supply-side factors. Based on the demand-side that the rising world demand for agricultural commodity price due to the increasing population, rapid economic grow and rising private consumption; the increase production of ethanol and biodiesel, the weakening of dollar; and increased speculation activity in future markets are considered as demand-driven factors to the increasing of agricultural commodity price. For the supply side, because of weather conditions make slow growth in agricultural production, soaring crude oil prices and are drought are more prounced supply-side explanations. 
Based on the demand-side factor, a negative relationship between the value of the dollar and dollar price of commodities follows from the law of one price for tradable goods. Accordingly, a decline in the value of the dollar must be outweighted by an increase in the dollar price of commodities and/or a fall in their foreign currency prices to ensure the same price when measured in dollars. Moreover, as many commodities are priced in dollars in international markets, a weaker dollar may raise the purchasing power and commodity demand of foreign consumers, while reducing the returns of foreign commodity suppliers and possibly their supplies.(Akram, 2009, Hamilton, 2008). The price impact of shifts in demand supply of commodities may be large if the demand or supply of commodities is relatively price inelastic, which is generally believed to be the case for many commodities and especially crude oil (Hamilton, 2008).

Arezki et al. (2014) stated that commodity currency theory provides the relationship between the level of exchange rate and the level of commodity price. Their finding suggests that gold price volatility plays a key role in explaining the exchange rate volatility. Reboredo and Rivera-Castro (2013) used couplas to study the relationship between the USD exchange rate and price for food(corn, soybean, wheat and rice). Their empirical evidence indicated that there was low and positive average dependence and tail independence between the USD and corn, and wheat, and average dependence and tail independence for rice. Akram (2009) investigate whether a decline in real interest rates and US dollar contributes to higher commodity prices. The evidence suggested that a weaker dollar leads to higher commodity prices.

A number of theoretical models have discussed the energy price (oil) and exchange rate relationship. For example, Chang (2014) investigated both the static and dynamic relationships between daily crude oil returns. Empirical results indicated that oil and exchange rate returns are both positive and symmetrical shows that move in the same direction. Lizardo and Mollick (2010) found that oil price significantly explain movements in the value of U.S. dollar again major currency from 1970 to 2008. Increase in oil prices lead to a significant depreciation of the U.S.D against Canada, Mexico and Russia. Ding and Vo (2012) used the multivariate stochastic volatility (MSV) and the multivariate GARCH (MGARCH) models to investigate the volatility interaction between the oil market and the foreign exchange market. They found that before the 2008 crisis, both oil and exchange rate markets respond to stock simultaneously and no interaction is detected. However, during turbulent time, there is bi-directional volatility interaction between the two.

Dauvin (2014) investigated the relationship between energy prices and the real effective exchange rate of commodity-exporting countries. Empirical results provide evidence of the existence of "energy-currencies". When the market is highly volatile, currencies follow an oil currency regime, term of trade becoming an important driver of the exchange rate.

Recently, owing to increased use of biofuels, including bioethanol and biodiesel, the relationship between the oil market and the agricultural market has become closer (Chang \& Su, 2010). The observed co-movement has led many researchers to examine the transmission mechanisms among energy and agricultural commodity prices. One is the direct effects from oil prices to agricultural commodity prices. It is argued that the soaring oil price result in higher agricultural commodity prices through cost-push effects by increasing cost of production and through higher demand of the agricultural commodities in biofuel production by increasing the demand for biofuels. The second link is the indirect effect of energy prices on food commodity prices through the exchange rate. A rise in oil price leads to exchange rate effects by increasing current account deficit which depreciates the local currency.

Frankel (2014) present and estimated a model of the prices of oil and other storable commodities, a model that can be characterized as reflecting the carry trade. Some evidences was found of a negative effect of interest rates on the demand for inventories and thereby on commodity prices and positive effects of expected future price gains on inventory demand and thereby on today's commodity prices. Zazlioglu and Soytas (2012) employed panel cointegration and Granger causality method to examine the dynamic relationship between oil prices and twenty four world agricultural commodity prices accounting for the changes in the relative strength of US dollar in a panel setting. The empirical results provide strong evidences on the impact of world oil price changes on agricultural commodity prices. Du et al. (2011) assessed the roles of various factors influencing the volatility of crude oil prices and the possible linkage between this volatility and agricultural commodity markets. They found evidence of volatility spillover among crude oil, corn, and wheat market after the fall of 2006 . This could be largely explained by tightened interdependence between these markets induced by ethanol production.

Ji and Fan (2012) by including the US dollar exchange rate as exogenous shock investigated price and volatility spillover between commodity markets by constructing a bivariate EGARCH model with time-varying correlation construction. The results reveal that the crude oil market has significant volatility spillover effects on non-energy 
commodity markets. In addition, the influence of the US dollar on commodity markets has weakened since the 2008 financial crisis.

Nazlioglu and Soytas (2011) examined the short-and long-run interdependence between oil price, lira-dollar exchange rate, and individual agricultural commodity prices in Turkey. The impulse-response analysis suggests the Turkish agricultural prices do not significantly react to oil price and exchange rate shock in the short-run. In addition, the changes in oil prices and exchange rate are not transmitted to agricultural commodity prices in Turkey. Hamilton and Wu (2015) studied data since 2006 to look for a systematic relation between the notional value of commodity futures contract held on behalf of index-fund investors and expected returns on future contracts. They found essentially no relation for the 12 agricultural commodities for which the CFTC reports such positions.

In contrast with previous works, this paper focus on volatility interaction between USD exchange rate, energy equity commodity and agricultural equity commodity CRB index. We use the "volatility surprise" component in multivariate (instead of univariate) GARCH models. It is obviously that previous analysis focus on the volatility mean or variance spillover effects among USD exchange rate, agricultural commodities and energy price markets. In our paper we extend the analysis by adopting the "volatility surprise" into our analysis to analyze the extent of cross-market linkages over different assets classes: dollar-energy-agricultural markets. It is the key contribution is to be cross-correlated with volatility surprise in those asset markets. There will be two-step econometric methodology. First, we calculate the mean-zero "volatility surprise" component results from univariate GARCH models. Second, we apply the MGARCH model to estimate the cross-market perspective.

The remainder of this paper is organized as follows. Section 2 outline the volatility surprise model and presents a description of the MGARCH models proposed. Section 3 describes the data sets and summary statistics. Section 4 contains the empirical findings and results. Section 5 is the conclusion.

\section{Model}

There are two parts of this section. The first part is to estimate and obtain the mean-zero "volatility surprise" component. The second part is to introduce the multivariate GARCH related models (BEKK, CCC, DCC, VARMA-CCC and VARMA-DCC).

\subsection{The Volatility Surprise Model}

Aboura and Chevallier $(2015,2014)$ following Engle (1993) define the "volatility surprise" as the volatility component that cannot be forecast, coined "volatility surprise". Consider the mean equation of a standard $\operatorname{GARCH}(1,1)$ specification as follows:

$$
R_{i t}=U_{i t}+\varepsilon_{i t}
$$

Where $R_{i t}$ is the asset price return of $i$ at time $t, \varepsilon_{i t}$ is the residual error term for $i$ asset at time $t$. $U_{i t}$ is the mean of asset $i$ at time $t$. The main objective of the time-varying conditional $\sigma_{t}$ is used to capture as much of the conditional variance in the residual $\varepsilon_{i t}$ as belows:

$$
\sigma_{t}^{2}=w+\alpha \varepsilon_{t-1}^{2}+\beta \sigma_{t-1}^{2}
$$

Engle (1993) definded the "volatility surprise", $\overline{\mathrm{S}}$, as the difference between the squared residual $\varepsilon_{i t}^{2}$ and the conditional variance $\sigma_{i t}^{2}$. For scaling purpose, we normalize this quantity by the conditional variance $\sigma_{i t}^{2}$. Here the normalized volatility surpise, $\overline{\mathrm{S}}$, is given by:

$$
\overline{S t}=\left(\varepsilon_{i t}^{2}-\sigma_{i t}^{2}\right) / \sigma_{i t}^{2}
$$

This residual are extracted from the mean equation of the conditional variance, which is chosen among appropriate GARCH specifications using an AIC criterion. Since by construction $E\left(\varepsilon_{i t}^{2} \mid R_{i, t-1}\right)=\sigma_{i t}^{2}$ then we obtain $\frac{E\left(\varepsilon_{i t}^{2} \mid R_{i, t-1}\right)-\sigma_{i t}^{2}}{\sigma_{i t}^{2}}=0$. Hence, we verify that the conditional mean is zero and can be as an input to any multivariate GARCH model.

\subsection{Multivairate GARCH Models}

Mulitvariate GARCH model (hence forth, MGARCH) models are useful developments regarding the parameterization of conditional dependence. Different class of MGARCH models have been proposed in the literature. One of the most general MGARCH(p,q) models is the BEKK representation (Engle \& Kroner, 1995). We try to investigate the "volatility surprise" spillover between the US dollar exchange rate and commodity index price markets by employ the multivariate BEKK-GARCH model. The BEKK model for multivariate 
$\operatorname{GARCH}(1,1)$ is given as below:

$$
H_{t}=C^{\prime} C+A^{\prime} \varepsilon_{t-1} \varepsilon^{\prime}{ }_{t-1} A+B^{\prime} H_{t-1}+B
$$

Here, the elements for the matrices $C, A$, and $\mathrm{B}$ are given as:

$$
A=\left[\begin{array}{lll}
\alpha_{11} & \alpha_{12} & \alpha_{13} \\
\alpha_{21} & \alpha_{22} & \alpha_{23} \\
\alpha_{31} & \alpha_{32} & \alpha_{33}
\end{array}\right], B=\left[\begin{array}{lll}
\beta_{11} & \beta_{12} & \beta_{13} \\
\beta_{21} & \beta_{22} & \beta_{23} \\
\beta_{31} & \beta_{32} & \beta_{33}
\end{array}\right], C=\left[\begin{array}{ccc}
C_{11} & 0 & 0 \\
C_{21} & C_{22} & 0 \\
C_{31} & C_{32} & C_{33}
\end{array}\right]
$$

Here, $H_{t}$ is the conditional covariance matrix. In the diagonal representation of this model diag(BEKK), the conditional variances are functions of their own lagged values and lagged square returns shocks. In addition, the conditional covariances are functions of the lagged covariances and lagged cross-products of the corresponding returns shocks. Here, $\mathrm{H}_{\mathrm{t}}$ is to be positive definite at all time $t$. The full BEKK process is stationary if and only if $A \otimes A+B \otimes B$ is less than one in modulus, where $\otimes$ is the kronecker product of two matrices. If $\mathrm{A}$ and $\mathrm{B}$ are two diagonal matrices, the sufficient conditional of stationarity is $\alpha_{i t}^{2}+\beta_{i t}^{2}<1, i=1,2$.

To investigate the correlations among several variables. Consider the CCC multivariate GARCH model of Bollerslev (1990) as bellows:

$$
R_{t}=E\left(R_{t} \mid F_{t-1}\right)+U_{t}, U_{t}=D_{t} \eta_{t}, \operatorname{var}\left(U_{t} \mid F_{t-1}\right)=D_{t} \Gamma D_{t}
$$

Where $R_{t}=\left(R_{1 t} \ldots R_{m t}\right)^{\prime}$ is a vector of returns, and $\eta_{t}=\left(\eta_{1 t} \ldots \eta_{m t}\right)^{\prime}$ is a sequence of indepently and identically distributed (i.i.d) random vectors, and $F_{t}$ is the past information available at time t. $D_{t}$ is equal to $\operatorname{diag}\left(\mathrm{h}^{1 / 2} \ldots \mathrm{h}_{\mathrm{m}}^{1 / 2}\right), m$ is the number of variables and $t=1,2 \ldots \mathrm{n}$. As $\Gamma=E\left(\eta_{t} \eta_{t^{\prime}}{ }^{1 / F_{t-1}}\right)=E\left(\eta_{t} \eta_{t}{ }^{\prime}\right)$, where $\Gamma=\left\{e_{i j}\right\}$ for $i, j=1 \ldots \mathrm{m}$, the constant conditional correlation matrix of the unconditional shocks, $\eta_{t}$ is equal to the constant conditional covariance matrix of the conditional shocks, $U_{t} \cdot U_{t} U_{t}{ }^{\prime}=D_{t} \eta_{t} \eta_{t}{ }^{\prime} D_{t}, D_{t}=\operatorname{diag}\left(Q_{t}\right)^{1 / 2}$, and $E\left(U_{t} U_{t}^{\prime} \mid F_{t-1}\right)=Q_{t}=D_{t} \Gamma D_{t}$, where $Q_{t}$ is sthe conditional covariance matrix. The conditional variance are positive and the correlation matrix $\Gamma=\left\{e_{i j}\right\}$ is positive definite. Next, this paper let $S_{t}$ denote a nx 1 vector of volatility surprises at time $t$, which is assumed to be conditionally normal with mean zero and covariance $n x n$ matrix $H_{t}$ :

$$
S_{t} \mid \Omega_{t-1 \sim} N\left(0 . H_{t}\right)
$$

Where $\Omega_{t-1}$ represents the information available at time $t-1$. The conditional covariance matrix $H_{t}$ can be decomposed as follows (Engle, 2009):

$$
H_{t}=D_{t} R_{t} D_{t}
$$

Where $\mathrm{D}_{\mathrm{t}}=\operatorname{diag}\left(\mathrm{h}_{11, \mathrm{t}} 1 / 2 /, \ldots \ldots \mathrm{h}_{33, \mathrm{t}}{ }^{1 / 2}\right)$ is the nxn diagonal matrix of time-varying standard deviations extracted from univariate GARCH model, $R_{t}=\left(e_{i j, t}\right), i, j=1,2,3$, assumes a time-dependent conditional correlation matrix, $\mathrm{h}_{i j, t}$ is defined as $\operatorname{GARCH}(1,1)$ specification on, $i . e_{.}, \mathrm{h}_{i j, t},=w+\alpha \varepsilon_{i, t-1}^{2}+\beta h_{i, t-1_{\mathrm{i}}}^{2}, i=1,2,3$ and

$$
R_{t}=\operatorname{diag}\left(\mathrm{q}_{i i, t}-1 / 2\right) / Q_{t} \operatorname{diag}\left(\mathrm{q}_{i i, t}{ }^{-1 / 2}\right)
$$

The covariance matrix $Q_{t}$ of the DCC model envoles according to:

$$
Q_{t}=\left(\bar{Q}-A^{\prime} \bar{Q} A-{B^{\prime}}^{-} \bar{Q} B\right)+A^{\prime}\left(l_{t-1} l_{t-1}^{\prime}\right) A+B^{\prime\left(Q_{t-1}\right)} B
$$

Where the unconditional covariance matrix $Q$ is composed of the $n$ time $n$ vector of standardized residuals, $l_{i, t}=\varepsilon_{i t} / h_{i t}$ computed from the first step procedure for which $l_{i, t} \rightarrow N\left(0, R_{t}\right)$. A and B are nxn diagonal matrix where $A=\operatorname{diag}(a)^{\frac{1}{2}}$ and $B=\operatorname{diag}(b)^{\frac{1}{2}}$. With the $3 \times 3$ symmetric positive-definite matrix $Q_{t}=\left\{q_{i j}, t\right\}, i, j=$ 1,2,3. Give by

$$
Q_{t}=(1-\alpha-\beta) \bar{Q}+\alpha U_{t-1^{\prime}} U_{t-1}^{\prime}+\beta Q_{t-1}
$$

Where $U_{i t}=\varepsilon_{i t} / \sqrt{h_{i t}} \cdot \bar{Q}$ is the $3 \times 3$ unconditional variance matrix of $U_{t}$, and $\alpha$ and $\beta$ are non-negative adjustment parameters satisfying $\alpha+\beta<1$. $Q_{t}$ basically resembles an autoregressive moving average (ARMA) type process which captures short-term deviations in the correlation around its long-run level. The variance-covariance matrix permit us to model the degree of volatility interdependence between markets across time.

In this study, the VARMA-GARCH of Ling and McAleer (2003) are used to model the volatility dynamics and conditional correlations between dollar exchange rate and commodity price. The VARMA-GARCH approach to modeling the conditional variance allows large shocks to one variable to affect the variance of the other variables. The VARMA-GARCH $(1,1)$ model used to model the time varying and covariance as: 


$$
\begin{gathered}
R_{i t}=E\left(R_{i t} \mid F_{t-1}\right)+\varepsilon_{t} \\
\phi(L)\left(R_{t-1}\right)=\Psi(L) \varepsilon_{t} \\
\varepsilon_{t}=D_{t} \eta_{t} \\
H_{t}=A_{t}+\sum_{i=1}^{r} B_{i} \overrightarrow{\varepsilon_{t-l}}+\sum_{j=1}^{s} C_{j} H_{t-j}
\end{gathered}
$$

Here $R_{i t}$ is the return for assets $i$ at time $t, F_{t-1}$ is the past information available at time t. $\phi(L)=l_{m}-\phi, L-$ $\cdots-\phi_{P} L^{p}$ and $\Psi(L)=l_{m}-\Psi_{1} L-\cdots-\Psi_{q} L^{q} \quad$ are polynomials in lag operator. $H_{t}=\left(\mathrm{h}_{1 \mathrm{t}} \cdots \mathrm{h}_{\mathrm{mt}}\right)$, $\eta_{t}=\left(\eta_{1 t} \ldots \eta_{m t}\right)^{\prime}, A_{t}=\left(W_{1 t} \ldots W_{m t}\right)^{\prime}, \overrightarrow{\varepsilon_{t}}=\left(\varepsilon_{1 \mathrm{t}}^{2} \ldots \varepsilon_{\mathrm{mt}}\right)^{\prime} \mathrm{D}_{\mathrm{t}}$ is $\operatorname{diag}\left(\mathrm{h}_{\mathrm{t}}{ }^{1 / 2}\right)$, and $m$ is the returns to be analyze and $t=1 \ldots m . B_{i}$ and $C_{j}$ are $m x m$ matrices with $\alpha_{i j}$ and $\beta_{i j}$, respectively. For $i, j=1 \ldots m$ are mxm matrices and represent the ARCH and GARCH effects, respectively. Spillover effects of the conditional variance between dollar exchange rate and commodity price are given in conditional volatility for each market in the portfolio.

\section{Data and Descriptive Statistics}

The CRB index, which is the most authoritative indicator reflecting commodity price changes, was selected as the representative commodity price for our research. The CRB index categories include energy (for example, crude oil, heating oil, natural gas), crops (for example, soybean, wheat, corn, sugar, coffee, live cattle, and cocoa), metals(for example, gold, silver, copper, aluminum and nickel). According to CRB classification, we choose CRB commodity equity index (COM), CRB agricultural equity index (AGR), CRB precious metal equity index(PRE), CRB energy index (ENE) and the US dollar index (DOL) was selected to represent changes in the US exchange rate. All the data are daily log returns over the period from 8 Oct. 2004 to 30 Sep. 2014, totally 2573 observations.

Descriptive statistics for volatility surprise for each commodity and the US dollar index are presented in Table 1. All the returns exhibit a higher degree of Kurtosis with a fat tail and non-normal distribution as verified by Jarqua-Bera test indicated positive and statistically significant reject the normal hypothesis. The mean for volatility surprise is positive for agricultural and industrial commodity index and negative for other commodity index and dollar exchange rate index. According to the standard deviation of Table 1, the agricultural commodity index volatility surprise is strongest (2.2422) and the industrial commodity index is weakest (1.7553). Therefore, the non-normality of the volatility surprise provide evidence of MGARCH model can modeling the volatility surprise suitable.

Table 1. Descriptive statistics

\begin{tabular}{lrrrrr}
\hline Variables & Mean & Std.Dev & Skewness & \multicolumn{1}{c}{ Kurtosis } & \multicolumn{1}{l}{ J-B } \\
\hline AGRVOL & 0.0030 & 2.2422 & 9.8517 & 183.3732 & $281.7635^{* * *}$ \\
COMVOL & -0.0045 & 1.9106 & 5.4382 & 52.3517 & $218.5702^{* * *}$ \\
ENEVOL & -0.0127 & 1.7717 & 4.2063 & 29.6078 & $666.4781^{* * *}$ \\
PREVOL & -0.0009 & 1.7749 & 4.5529 & 37.3416 & $108.0284^{* * *}$ \\
DOLVOL & -0.0004 & 1.7580 & 3.9989 & 26.8771 & $542.6670^{* * *}$ \\
\hline
\end{tabular}

Note. $* * *, * *, *$ indicated at least significant at $1 \%, 5 \%$ and $10 \%$ levels, respectively.

\section{Empirical Findings}

This section shows parameter estimates for five multivariate GARCH model. The five multivariate GARCH models, name as BEKK-MGARCH, CCC-MGARCH, DCC-MGARCH, CCC-VARMA-GARCH, and DCC-VARMA-GARCH models are estimated and analyze the mean and volatility surprise spill over among dollar exchange rate and various commodity markets. Based on the Akaike Information Criterion (AIC), the optimal lag number is equal to one. The estimated results in Table 2 indicated that the mean and volatility spillover effect of volatility surprise of the dollar exchange rate market, agricultural commodity market and energy commodity market.

\subsection{Volatility Surprise of Dollar Exchange Rate, Agricultural and Energy Commodity Markets}

According to the estimation of own effect, volatility surprise of returns for dollar exchange rate are mainly dependent on their own past values, as measured by coefficients Bii in five MGARCH models. This finding shows the evidence of short-term predictability in dollar exchange rate changes through time. For the mean equation of the dollar exchange rate, the positive coefficient show energy commodity market mean spillover across to the dollar exchange rate index market. Sharply increase in the price of energy commodity volatility 
surprise positively increase the price of volatility surprise in the dollar exchange rate are found the consistent results in the five MGARCH models.

Turing to the variance equation, the elements of the A matrix are estimated coefficients for the ARCH volatility which measures the short-term volatility persistence. According to the estimation results of own conditional $\mathrm{ARCH}$ effects, the positive or negative significant at $1 \%$ level, which indicated that there are evidence of short-term volatility persistence. According to the BEKK-MGARCH, VARMA-CCC and VARMA-DCC can help to measure the short-term volatility spillover across asset markets. Statistically significant negative of A $(3,1)$ show that increase of the volatility surprise of the energy market decrease the volatility surprise of the dollar exchange rate. In addition, we also find the strong volatility surprise spillover effect from dollar exchange rate market to agricultural commodity market and also agricultural commodity market to energy commodity market. Therefore, the significant volatility surprise short run persistence effect was found among dollar exchange rate, agricultural, and energy commodity markets. The short-run volatility surprise spillover effect exists in the five MGARCH models.

Turn to the variance equation, the own conditional GARCH effect (Bii), the elements of B matrix are the estimated coefficients for the GARCH volatility which measures the long-term persistence. Based on the estimated result of Table 3, the estimated coefficients of own conditional GARCH effects are positive or negative statistically significant at $1 \%$ level indicated that of own long-term volatility persistence. According to variance equation, we observed that in addition to own past innovations, the conditional variance in each market is also affected by innovations coming at least from one of the other markets.

Table 2. MGARCH parameter estimates for dollar exchange rate, CRB agricultural and energy index

\begin{tabular}{|c|c|c|c|c|c|}
\hline Coefficient & BEKK & $\mathrm{CCC}$ & DCC & VARMA-CC & VARMA-DCC \\
\hline \multicolumn{6}{|l|}{ Mean } \\
\hline B10 & 0.0003 & -0.0152 & 0.0051 & $0.0345^{* * *} *$ & $0.0134 * * *$ \\
\hline B11 & $-0.0701 * * *$ & $\begin{array}{r}-0.0607 * * \\
*\end{array}$ & $-0.0583 * * *$ & $-0.0951 * * *$ & $-0.1238 * * *$ \\
\hline B12 & 0.0106 & 0.0143 & -0.0171 & $0.0063^{* * *}$ & $-0.0122 * * *$ \\
\hline B13 & $0.0784 * * *$ & $0.0459 * * *$ & $0.1017 * * *$ & $0.0489 * * *$ & $0.1021 * * *$ \\
\hline B20 & -0.0284 & $0.0011^{* * *}$ & -0.0044 & $-0.0311 * * *$ & $-0.0039 * * *$ \\
\hline B21 & 0.0042 & $\begin{array}{r}-0.0038 * * \\
*\end{array}$ & -0.0063 & $0.0275^{* * *}$ & -0.0330 *** \\
\hline B22 & -0.0225 & $\begin{array}{r}-0.0149 * * \\
*\end{array}$ & 0.0107 & $-0.0241 * * *$ & $0.0067 * * *$ \\
\hline B23 & 0.0109 & $0.0182 * * *$ & -0.0015 & $0.01788 * * *$ & $-0.0150 * * *$ \\
\hline B30 & -0.0644 & -0.0158 & -0.0228 & $-0.01269 * * *$ & $-0.0441 * * *$ \\
\hline B31 & 0.0087 & 0.0103 & -0.0151 & $0.0178^{* * *}$ & $-0.0506^{* * *}$ \\
\hline B32 & -0.0531 & -0.0211 & -0.0150 & $-0.0028 * * *$ & $-0.0126^{* * * *}$ \\
\hline B33 & 0.0048 & -0.0166 & 0.0106 & $-0.0081 * * *$ & $-0.0004 * * *$ \\
\hline \multicolumn{6}{|l|}{$\underline{\text { Variance }}$} \\
\hline $\mathrm{C}(1,1)$ & $1.3583^{* * *}$ & $1.7901^{* * *}$ & 1.5922 & $2.1734^{* * * *}$ & $3.1388^{* * * *}$ \\
\hline $\mathrm{C}(2,1)$ & -0.4668 & & & & \\
\hline $\mathrm{C}(2,2)$ & $1.3588 * * *$ & $3.2543 * * *$ & $9.1792 * * *$ & $2.8158 * * *$ & $4.4148 * * *$ \\
\hline $\mathrm{C}(3,1)$ & -0.0883 & & & & \\
\hline $\mathrm{C}(3,2)$ & -0.3783 & & & & \\
\hline $\mathrm{C}(3,3)$ & -0.0000 & $1.8380 * * *$ & $0.4623^{* * *}$ & $1.1433 * * *$ & $0.3233 * * *$ \\
\hline $\mathrm{A}(1,1)$ & $0.6726 * *$ & $\begin{array}{r}-0.0078 * * \\
*\end{array}$ & -0.0040 & $0.0336 * * *$ & $0.0263 * * *$ \\
\hline $\mathrm{A}(1,2)$ & 0.0359 & & & $-0.0355^{* * *}$ & $0.0252 * * *$ \\
\hline $\mathrm{A}(1,3)$ & 0.0322 & & & $0.0053^{* * *}$ & $-0.0384 * * *$ \\
\hline $\mathrm{A}(2,1)$ & $-0.1739 * * *$ & & & $0.0146^{* * * *}$ & $-0.0499 * * *$ \\
\hline $\mathrm{A}(2,2)$ & $0.4787 * * *$ & -0.0017 & $0.0019 * * *$ & $-0.0009 * * *$ & $0.0625 * * *$ \\
\hline $\mathrm{A}(2,3)$ & $0.5654 * * *$ & & & $0.0074 * * *$ & $-0.0462 * * *$ \\
\hline $\mathrm{A}(3,1)$ & $-0.1620 * * *$ & & & $-0.0006 * * *$ & $-0.0339 * * *$ \\
\hline $\mathrm{A}(3,2)$ & $-0.2451 * * *$ & & & $0.1015^{* * *} *$ & $0.1054 * * *$ \\
\hline
\end{tabular}




\begin{tabular}{|c|c|c|c|c|c|}
\hline $\mathrm{A}(3,3)$ & $-0.3307 * * *$ & $0.0554 * * *$ & $0.0228 * * *$ & $-0.0261 * * *$ & $-0.0284 * * *$ \\
\hline $\mathrm{B}(1,1)$ & $-0.4244 * * *$ & $0.4238 * * *$ & 0.4838 & $0.2553^{* * *}$ & $0.0109^{* * *}$ \\
\hline $\mathrm{B}(1,2)$ & $-0.2592 * *$ & & & $0.1262 * * *$ & $0.0517 * * *$ \\
\hline $\mathrm{B}(1,3)$ & -0.1590 & & & $-0.0065 * * *$ & $-0.1989 * * *$ \\
\hline $\mathrm{B}(2,1)$ & 0.3793 & & & $-0.0276^{* * *}$ & $-0.0049 * * *$ \\
\hline $\mathrm{B}(2,2)$ & $0.8081^{* * *}$ & $0.3577 * * *$ & $-0.8216^{* * *}$ & $0.4409 * * *$ & $-0.0172^{* * *}$ \\
\hline $\mathrm{B}(2,3)$ & $0.6230 * * *$ & & & $0.0070 * * *$ & $0.3313 * * *$ \\
\hline $\mathrm{B}(3,1)$ & -0.1644 & & & $0.2030^{* * *}$ & $0.0227 * * *$ \\
\hline $\mathrm{B}(3,2)$ & $-0.2303^{* *}$ & & & $-0.0275 * * *$ & $0.4431 * * *$ \\
\hline $\mathrm{B}(3,3)$ & $0.1764 * *$ & $0.3851 * * *$ & $0.8285^{* * *}$ & $0.5644 * * *$ & $0.5232 * * *$ \\
\hline $\mathrm{R}(2,1)$ & & $0.1626^{* * *}$ & & $0.1361 * * *$ & \\
\hline $\mathrm{R}(3,1)$ & & $0.2553^{* * * *}$ & & $0.2248^{* * *} *$ & \\
\hline $\mathrm{R}(3,2)$ & & $0.5748^{* * *}$ & & $0.5738^{* * *}$ & \\
\hline $\operatorname{DCC}(1)$ & & & $0.0725 * * *$ & & $0.1759 * * *$ \\
\hline $\operatorname{DCC}(2)$ & & & $0.0735^{* *}$ & & $0.1009 * * *$ \\
\hline $\log L$ & 13025.0211 & $\begin{array}{r}13157.723 \\
3\end{array}$ & 13311.4710 & 13379.5244 & 13415.4771 \\
\hline AIC & -11.7960 & -11.4450 & -11.8022 & -12.0536 & -12.2237 \\
\hline SBC & -10.8851 & -10.7633 & -11.4335 & -11.7944 & -12.1066 \\
\hline
\end{tabular}

Table 3. Residual diagnostic test for MGARCH models of dollar exchange rate, CRB agricultural and energy index

\begin{tabular}{|c|c|c|c|c|c|c|c|c|c|c|c|c|c|c|c|}
\hline & \multicolumn{3}{|c|}{ BEKK } & \multicolumn{3}{|c|}{$\mathrm{CCC}$} & \multicolumn{3}{|c|}{ DCC } & \multicolumn{3}{|c|}{ VARMA-CC } & \multicolumn{3}{|c|}{ VARMA-DCC } \\
\hline & DOL & AGR & EAE & DOL & AGR & EAE & DOL & AGR & EAE & DOL & AGR & EAE & DOL & AGR & EAE \\
\hline ARCH-LM & 0.9122 & 0.7731 & 1.1125 & 1.5851 & 0.8762 & 0.9709 & 2.0153 & 1.6670 & 1.5123 & 1.3327 & 0.4105 & 0.8505 & 0.7778 & 2.0597 & 1.7657 \\
\hline Q-stat. & 18.1415 & 11.9000 & 22.3971 & $25.7747 *$ & 19.7147 & 22.1577 & 10.8915 & 18.7111 & 20.5113 & 12.8816 & 17.1569 & 10.1168 & 19.2106 & 21.7010 & 23.4850 \\
\hline Q2-stat. & 9.7695 & 4.5166 & 5.7815 & 7.3371 & 7.8153 & 4.8872 & 6.9078 & 10.5113 & 7.9953 & 6.7831 & 7.0522 & 8.6974 & 5.5666 & 11.0456 & 11.1847 \\
\hline
\end{tabular}

Next, for the DCC model, the estimates of the DCC and VARMA-DCC parameters, DCC (1) and DCC(2), are statistically significant in all cases. This indicates that the assumption of constant conditional correlation for all shocks to return is not supported empirically. The short run persistence of shocks on the dynamic conditional correlations is greatest for VARMA-DCC at 0.1759, while the largest run persistence of shocks to the conditional correlations is $0.2768(=0.1759+0.1009)$ for VARMA-DCC models. These estimated coefficients sum to a value less than one, indicating that the dynamic conditional correlation are mean reverting and the significantly coefficients leading to a rejection of the assumption of CCC for all news to return. The magnitude of the DCC estimator of the VARMA is greater than DCC model. The estimated coefficient of the AIC and SBC criteria from Table $\mathrm{X}$ show that the VARMA-DCC model is the best model in five models. Residual diagnostic test coefficients of the ARCH-LM exhibit no statistically significant ARCH effect or no evidence of autocorrelation in the standardized result at $1 \%$ level. In addition, the estimated values of Q-statistics and Q-square statistics show no serial autocorrelation or heteroskedasticity for each variable in five models. According to the residual diagnostic test, the VARMA-DCC model is the best model for modeling the conditional volatility surprise variables.

\subsection{Volatility Surprise of Dollar Exchange Rate, Commodity and Precious Metal Equity Market}

The estimated coefficients of own effects of dollar exchange rate volatility surprise are negative and statistically significant at $1 \%$ level. This empirical result show that the evidence of short-term predictability in dollar exchange rate volatility surprise. The cross mean spillover effect show that strong effects of precious metal index to dollar exchange rate and feed-back effects. Next, from the variance equation, the estimated coefficient of own conditional ARCH effects show significant evidence of strong effects indicated that of own short-term volatility persistence. The negative and statistically significant coefficient of $A(3,1)$ show that the volatility surprise of dollar exchange rate will cross negatively affected to the precious metal commodity equity index. The strong cross volatility surprise spillover effect also for the commodity equity index to the precious metal commodity index. 
The estimated coefficients of own conditional GARCH effect from variance equation of Table 6, which measures the long-term persistence. The positive or negative statistically significant coefficients indicated that the strong own conditional GARCH effect and long-term volatility persistence. The strong cross volatility surprise volatility spillover effect was found from precious metal equity index to the commodity equity index and also the commodity equity index to the dollar exchange rate.

According to the DCC model, the estimated coefficients of the DCC parameters DCC(1) and DCC(2) are positively and statistically significant at $1 \%$ level between DCC and VARMA-DCC MGARCH models. The estimated parameters of DCC(1) and DCC(2) sum to a value which is less than one, showing that the dynamic conditional correlations are mean reverting and the significantly coefficients leading to a rejection of the assumptions of CCC for all news to return markets. The short-run persistence of shocks on the DCC(1) is higher for VARMA-DCC than DCC $(0.0868>0.0518)$. However, the long-run persistence of shocks, DCC $(2)$, is larger for DCC than VARMA-DCC models (0.1191>0.0833).

Residual diagnostic test at Table 6 and 7, the estimated parameters of the AIC and SBC criterion show that the VARMA-DCC model is also the best model in five MGARCH models. Residual diagnostic test of the standardized residuals(Q-statics) display that no statistically significant evidence of autocorrelation in the standardized result at the $1 \%$ level. The insignificant estimated results of ARCH-LM value display that no significant ARCH effect exist at those models. The most suitable model was found for VARMA-DCC models at this case.

Table 4. MGARCH parameter estimates for dollar exchange rate, CRB commodity and precious metal index

\begin{tabular}{|c|c|c|c|c|c|}
\hline Coefficient & BEKK & $\mathrm{CCC}$ & DCC & VARMA-CC & VARMA-DCC \\
\hline \multicolumn{6}{|l|}{ Mean } \\
\hline B10 & 0.0003 & $0.0011^{* * * *}$ & $-0.0057 * * *$ & $0.0181 * * *$ & 0.0060 *** \\
\hline B11 & $-0.0701 * * *$ & $-0.0566 * * *$ & $-0.0568 * * *$ & $-0.0571 * * *$ & $-0.0584 * * *$ \\
\hline B12 & 0.0106 & $0.0549 * * *$ & $0.0750 * * *$ & $6.0626 * * *$ & 0.0918 *** \\
\hline B13 & $0.0784 * * *$ & $0.0031 * * *$ & $-0.0161 * * *$ & $-0.0063 * * *$ & $-0.0281 * * *$ \\
\hline B 20 & -0.0284 & -0.0048 & -0.0113 & $-0.0153 * * *$ & $-0.0093^{* * *}$ \\
\hline B21 & 0.0042 & -0.0029 & -0.0041 & $0.0241 * * *$ & $-0.0522 * * *$ \\
\hline B22 & -0.0225 & 0.0011 & -0.0241 & -0.0121 & -0.0032 \\
\hline B23 & 0.0109 & 0.0045 & $0.0469^{* * *}$ & $0.0173 * * *$ & 0.0450 *** \\
\hline B30 & $-0.0644^{*}$ & 0.0008 & -0.0060 & $0.0212 * * *$ & $0.0087 * * *$ \\
\hline B31 & 0.0087 & $-0.0231 *$ & -0.0313 & $0.0140^{* *}$ & $-0.0528 * * *$ \\
\hline B32 & -0.0531 & $0.0409^{* *}$ & 0.0023 & $0.0208^{*}$ & $0.0279 * * *$ \\
\hline B33 & 0.0048 & -0.0048 & 0.0425 & -0.0045 & $0.0250 * * *$ \\
\hline \multicolumn{6}{|l|}{ Variance } \\
\hline $\mathrm{C}(1,1)$ & $1.3583^{* * *}$ & $1.8481 * * *$ & $2.1167 * * *$ & $2.0291 * * *$ & $2.4555^{* * *}$ \\
\hline $\mathrm{C}(2,1)$ & -0.4667 & & & & \\
\hline $\mathrm{C}(2,2)$ & $1.3588 * * *$ & $1.7846^{* * * *}$ & $1.8141^{* * *}$ & $2.5256 * * *$ & $1.6958 * * *$ \\
\hline $\mathrm{C}(3,1)$ & -0.0883 & & & & \\
\hline $\mathrm{C}(3,2)$ & -0.3782 & & & & \\
\hline $\mathrm{C}(3,3)$ & 0.0000 & $1.3153 * * *$ & $2.4336^{* * *}$ & $2.5985^{* * * *}$ & $2.9995 * * *$ \\
\hline $\mathrm{A}(1,1)$ & 0.0727 & $-0.0082 * * *$ & $-0.0083 * * *$ & $-0.0076^{* * * *}$ & $-0.0092 * * *$ \\
\hline $\mathrm{A}(1,2)$ & 0.0359 & & & $-0.0163 * * *$ & $-0.0201 * * *$ \\
\hline $\mathrm{A}(1,3)$ & 0.0322 & & & $0.0138 * * *$ & $0.0321 * * *$ \\
\hline $\mathrm{A}(2,1)$ & $-0.1739 *$ & & & 0.0083 & $-0.0579 * * *$ \\
\hline $\mathrm{A}(2,2)$ & $0.4787 * * *$ & $0.0430 * * *$ & $0.0350 * * *$ & $0.1124 * * *$ & $-0.0014 * * *$ \\
\hline $\mathrm{A}(2,3)$ & $0.5654 * * *$ & & & $-0.0376 * * *$ & $0.0943 * * *$ \\
\hline $\mathrm{A}(3,1)$ & $-0.1620 * * *$ & & & $-0.0509 * * *$ & $-0.0242 * * *$ \\
\hline $\mathrm{A}(3,2)$ & $-0.2451 * * *$ & & & $-0.0827 * * *$ & $0.0182 * * *$ \\
\hline $\mathrm{A}(3,3)$ & $-0.3307 * * *$ & $0.0338 * * *$ & $0.0365^{* * *}$ & $0.2009 * * *$ & $0.0622 * * *$ \\
\hline $\mathrm{B}(1,1)$ & $-0.4244 * * *$ & $0.3998 * * *$ & $0.3205^{* * * *}$ & $0.3080 * * *$ & $0.2144 * * *$ \\
\hline $\mathrm{B}(1,2)$ & $-0.2592 * * *$ & & & $0.1183 * * *$ & -0.0896 *** \\
\hline $\mathrm{B}(1,3)$ & -0.1591 & & & $0.0068 * * *$ & $0.0366 * * *$ \\
\hline $\mathrm{B}(2,1)$ & 0.3793 & & & $-0.0849 * * *$ & $0.0345^{* * *}$ \\
\hline
\end{tabular}




\begin{tabular}{|c|c|c|c|c|c|}
\hline $\mathrm{B}(2,2)$ & $0.8081 * * *$ & $0.4775 * * *$ & $0.4691 * * *$ & $0.2815^{* * *}$ & $0.4888 * * *$ \\
\hline $\mathrm{B}(2,3)$ & $0.6230 * * *$ & & & $0.0212 * * *$ & $-0.0012 * * *$ \\
\hline $\mathrm{B}(3,1)$ & -0.1643 & & & $0.0425^{* * * *}$ & $-1.2745^{* * *}$ \\
\hline $\mathrm{B}(3,2)$ & -0.2303 & & & $0.0159 * *$ & $-0.0487 * * *$ \\
\hline $\mathrm{B}(3,3)$ & $0.1764 * *$ & $0.5538 * * *$ & $0.1841^{* * *}$ & $0.0922 * * *$ & 0.3440 *** \\
\hline $\mathrm{R}(2,1)$ & & $0.2680^{* * *}$ & & $0.2894 * * *$ & \\
\hline $\mathrm{R}(3,1)$ & & $0.2660 * * *$ & & $0.2878 * * *$ & \\
\hline $\mathrm{R}(3,2)$ & & $0.6397 * * *$ & & $0.6393^{* * *}$ & \\
\hline $\operatorname{DCC}(1)$ & & & $0.0518^{* * *}$ & & $0.0868 * * *$ \\
\hline $\mathrm{DCC}(2)$ & & & $0.1191 * *$ & & $0.0833^{* * *}$ \\
\hline $\log L$ & 12121.8245 & 12223.8355 & 12198.2559 & 12298.6476 & 12314.1388 \\
\hline AIC & -12.7451 & -12.4831 & -11.1203 & -12.3305 & -13.0032 \\
\hline SBC & -11.4335 & -10.1460 & -13.0574 & -12.1025 & -13.2553 \\
\hline
\end{tabular}

Table 5. Residual diagnostic test of MGARCH models for dollar exchange rate, CRB commodity and precious metal index

\begin{tabular}{|c|c|c|c|c|c|c|c|c|c|c|c|c|c|c|c|}
\hline & \multicolumn{3}{|c|}{ BEKK } & \multicolumn{3}{|c|}{$\mathrm{CCC}$} & \multicolumn{3}{|c|}{ DCC } & \multicolumn{3}{|c|}{ VARMA-CC } & \multicolumn{3}{|c|}{ VARMA-DCC } \\
\hline & DOL & $\mathrm{COM}$ & PRE & DOL & $\mathrm{COM}$ & PRE & DOL & $\mathrm{COM}$ & PRE & DOL & $\mathrm{COM}$ & PRE & DOL & $\mathrm{COM}$ & PRE \\
\hline ARCH-LM & 0.8216 & 0.9179 & 1.0583 & 1.5922 & 1.9179 & 0.9626 & 1.3415 & 0.8377 & 0.9629 & 0.8567 & 2.1823 & 2.2241 & 1.3119 & 1.3387 & 2.0211 \\
\hline Q-stat. & 22.873 & 27.240 & 21.120 & 19.224 & 21.999 & 23.121 & 23.251 & 21.442 & 20.230 & 22.191 & 21.269 & 25.274 & 25.165 & 23.393 & 29.539 \\
\hline$Q^{2}$-stat. & 4.8878 & 6.3136 & 9.1757 & 10.048 & 9.3963 & 9.5037 & 11.956 & 10.274 & 6.3136 & 13.313 & 12.583 & 11.567 & 13.343 & 9.1044 & 10.086 \\
\hline
\end{tabular}

\section{Conclusions}

There are a lot of previous literatures stated about that the volatility spillover effects among energy price market (for example, oil, electricity, gas and coal) and non-energy commodity price (for example, agricultural, precious metal). Just a few paper analyze the volatility spillover relationship between the dollar exchange rate and energy or non-energy commodity market.

Aboura and Chevallier (2014a, 2014b, 2015) introduced the "volatility surprise" component into the multivariate GARCH model to modeling the dynamic volatility spillover effects among commodity future markets. This paper by extend their analysis to analyze the volatility surprise effects among dollar exchange rate and CRB energy and non-energy commodity markets by using five MGARCH models which are BEKK, CCC, DCC, VARMA-CCC, and VARMA-DCC.

Empirical results show that significant own short-term and long-term persistence effects and also the cross-market spillover short-term and long-term persistence effect among dollar exchange rate and commodity future markets in five MGARCH models. In addition, based on the residual diagnostic test, we find that the VARMA-DCC model is the best model to modeling the dollar exchange rate and commodity future markets.

According to our analysis, the dollar exchange rate, energy commodity future market and non-energy commodity market (precious metal and agricultural market) are inter-correlated each other not only in the short-term but also in the long-term. Therefore, the change of the dollar exchange rate will affect the change of commodity future markets support the finding to the individual investors, policy makers and institutional investors.

\section{References}

Aboura, S., \& Chevallier, J. (2014), Volatility equicorrelation: A cross-market perspective. Economics Letters, 122, 289-295. http://dx.doi.org/10.1016/j.econlet.2013.12.008

Aboura, S., \& Chevallier, J. (2015). A cross-volatility index for hedging the country risk. Journal of International Financial Markets, Institutions \& Money, 38, 25-41. http://dx.doi.org/10.1016/j.intfin.2015.05.008

Akram, Q. F. (2009). Commodity price, interest rates and the dollar. Energy Economics, 31, 838-851. http://dx.doi.org/10.1016/j.eneco.2009.05.016

Arezki, R., Lederman, D., \& Zhao, H. (2014). The relative volatility of commodity prices: A reappraisal. American Journal of Agricultural Economics, 96, 939-951. http://dx.doi.org/10.1093/ajae/aat050 
Bollerslev, T. (1990). Modeling the coherence in short-run nominal exchange rates: A multivariate generalized ARCH model. Review of Economics and Statistics, 72, 498-505. http://dx.doi.org/10.2307/2109358

Chang, K. L. (2014). The symmetrical and positive relationship between crude oil and nominal exchange rate returns. North American Journal of Economics and Finance, 29, 266-284. http://dx.doi.org/10.1016/j.najef.2014.07.001

Chang, T. H., \& Su, H. M. (2010). The substitutive effect of biofuels on fossil fuels in the lower and higher crude oil price periods. Energy, 35(7), 2807-2813. http://dx.doi.org/10.106/j.energy.2010.03.006

Dauvin, M. (2014). Energy prices and the real exchange rate of commodity-exporting countries. Economie Internationale. CEPII research center, 137, 52-72.

Ding, L., \& Vo, M. (2012). Exchange rates and oil prices: A multivariate stochastic volatility analysis. The Quarterly Review of Economics and Finance, 52,15-47. http://dx.doi.org/10.1016/j.qref2012.01.003

Du, X., Cindy, L. Y., \& Hayes, D. J. (2011). Speculation and volatility spillover in the crude oil and agricultural commodity markets: A Bayesian analysis. Energy Economics, 33(3), 497-503. http://dx.doi.org/10.1016/j.eneco.2010.12.015

Engle, R. (1993). Technical note: statistical models for financial volatility. Financial Analysis Journal, 49, 72-78. http:dx.doi.org/10.1039/s0266366600005124

Engle, R. (2009). Anticipating correlations: A new paradigm for risk management (p. 154). USA: Princeton University Press.

Frankel, J. A. (2014). Effects of speculation and interest rates in a "carry trade" model of commodity prices. Journal of International Money and Finance, 42, 88-112. http://dx.doi.org/10.2286/w19463

Hamao, Y., Masulis, R. W., \& Ng, V. (1990). Correlations in price changes and volatility across international stock markets. The Review of Financial Studies, 3, 281-307. http://dx.doi.org/10.1093/rfs/3.2.281

Hamilton, J. D. (2008). Understanding crude oil price. NBER working paper, 14492.

Hamilton, J. D., \& Wu, J. C. (2015). Effects of index-fund investing on commodity futures prices. International Economic Review, 56(1), 187-205. http://dx.doi.org/10.3386/w19892

Ji, Q., \& Fan, Y. (2012). How does oil price volatility affect non-energy commodity markets? Applied Energy, 89, 273-280. http://dx.doi.org/10.1016/j.apenergy2011.07.038

Ling, S., \& McAleer, M. (2003). Symptotic theory for a vector ARMA-GARCH model. Econometric Theory, 19, 278-308. http://dx.doi.org/10.1017/s0266466603192092

Lizardo, R. A., \& Mollick, A. V. (2010). Oil price fluctuations and U.S. dollar exchange rates. Energy Economics, 32, 399-408. http://dx.doi.org/10.1016/j.eneco.2009.10.005

Nazlioglu, S., \& Soytas, U. (2011). World oil prices and agricultural commodity prices: Evidence from an emerging market. Energy Economics, 33, 488-496. http://dx.doi.org/10.1016/j.eneco.2010.11.012

Nazlioglu, S., \& Soytas, U. (2012). Oil price, agricultural commodity prices, and the dollar: A panel cointegration and causality analysis. Energy Economics, 34, 1098-1104. http://dx.doi.org/10.1016/j.eneco.2011.09.008

Reboredo, J. C., \& Rivera-Castro, M. A. (2013). A wavelet decomposition approach to crude oil price and $\begin{array}{lllll}\text { exchange rate } & \text { dependence. }\end{array}$ http://dx.doi.org/10.1016/j.econmod.2012.12.028

Ross, S. (1989). Information and volatility: The no-arbitrage martingale approach to timing and resolution irrelevancy. Journal of Finance, 44, 1-17. http://dx.doi.org/10.1111/j-1540-6261.1989

\section{Copyrights}

Copyright for this article is retained by the author(s), with first publication rights granted to the journal.

This is an open-access article distributed under the terms and conditions of the Creative Commons Attribution license (http://creativecommons.org/licenses/by/4.0/). 